\title{
Review
}

\section{Experimental diabetic neuropathy: an update}

\author{
A.A.F. Sima, K. Sugimoto \\ Departments of Pathology and Neurology, Wayne State University, School of Medicine and Detroit Medical Center, Detroit, \\ Michigan USA
}

\section{Abstract}

Diabetic neuropathy consists of several clinical syndromes affecting motor, sensory and autonomic nerves. Of these the most common is distal symmetric sensory polyneuropathy usually referred to as diabetic neuropathy. Animal studies, mainly in diabetic rodents, have contributed tremendously to our understanding of this disease. From these it is clear that the pathogenesis of diabetic neuropathy is multifactorial involving sequentially occurring and often closely interrelated metabolic aberrations. Major pathogenetic mechanisms include increased activity of the polyol pathway, abnormalities in vasoactive substances, non-enzymatic glycation, increased presence of free radicals, and perturbed neurotrophism. Traditionally the neuropathies accompanying Type I (insulin-dependent) and Type II (non-insulin-dependent) diabetes mellitus have been regarded as identical. Recent investigations have, however, clearly delineated distinct differences in the functional and structural expressions of the neuropathies in the two types of diabetes. Major future challenges are the identification of the differences in underlying pathogenetic mechanisms in the two types of neuropathy and in gaining a better understanding of the hierarchy of the multifactorial mechanisms underlying the disease. This will be important for designing meaningful therapies which to date have failed miserably in diabetic neuropathy. [Diabetologia (1999) 42: 773-788]

Keywords Neuropathy, pathogenesis, metabolism, physiology, pathology.
The peripheral nerve complications encountered in diabetes mellitus encompass a variety of abnormalities affecting both somatic and autonomic peripheral nerve function [1] and they are associated with the in-

Corresponding author: A. A.F. Sima MD, PhD, Department of Pathology, 9275 Gordon Scott Hall, Wayne State University, 540E, Canfield Avenue, Detroit, MI 48201, USA

Abbreviations: ACE, Angiotensin converting enzyme; AG, aminoguanidine; AGE, advanced glycation end product; ARI, aldose reductase inhibitor; BDND, brain derived neurotrophic factor; CML, $N^{\varepsilon}$-[carboxymethyl]-lysine; 3DG, 3-deoxyglucosone; GLUT, glucose transporter; GSH, glutathione; IGF-1R, insulin-like growth factor-1 receptor; IR, insulin receptor; $\mathrm{MGO}$, methylglyoxal; $\mathrm{NCV}$, nerve conduction velocity; $\mathrm{NF} \varkappa \mathrm{B}$, nuclear factor $\varkappa \mathrm{B}$; NGF, nerve growth factor; $\mathrm{NO}$, nitric oxide; NT-3, neurotrophin 3; NT 4/5, neurotrophin 4/5; ROS, reactive oxygen species; SOD, superoxide dismutase; STZ, streptozotocin. creased morbidity and mortality seen in diabetic patients $[1,2]$. The prevalence of clinically overt peripheral neuropathy is $7 \%$ within a year of diagnosis of diabetes and increases to $50 \%$ in patients with diabetes for more than 25 years [3]. If subclinical nonsymptomatic neuropathy is included the prevalence approaches $100 \%$. Diabetic neuropathies include several distinct syndromes of which symmetric sensory polyneuropathy, often associated with autonomic polyneuropathy, is the most common [1] and is usually referred to as diabetic neuropathy. The different syndromes can be separated into rapidly reversible manifestations and chronic syndromes. The latter can be further divided into symmetric polyneuropathies and focal and multifocal neuropathies [4].

The pathogenesis of diabetic neuropathy has been the subject of extensive research and some controversy over the last decade $[5,6]$ and has still not been ful- 


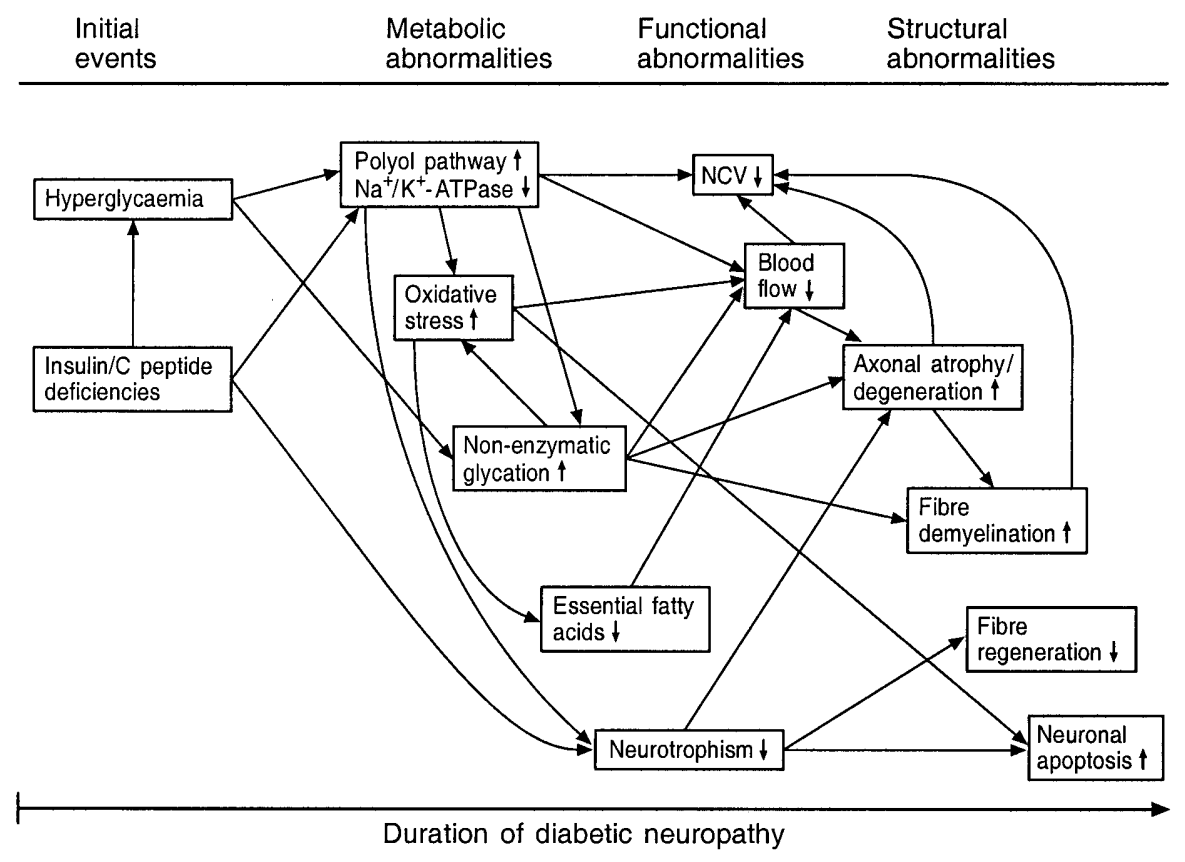

Fig. 1. The metabolic abnormalities induced by hyperglycaemia and insulin/C peptide deficiencies are multifold and appear to occur in a temporal sequence. The major metabolic abnormalities are commonly interactive and mutually perpetuating (see text). They lead to impaired nerve function and decreased blood flow, which initially are readily reversible. As structural changes emerge and progress, the functional abnormalities become increasingly less responsive to metabolic interventions

ly explored. There appears, however, to be agreement that the underlying causes of diabetic neuropathy are multifactorial, where distinct aberrations of specific metabolic pathways appear to be interrelated and mutually perpetuating [5-7]. Further, certain metabolic pathways of pathogenetic importance appear to be more relevant during particular phases of the clinical course of the disease (Fig.1). Accumulation of sorbitol from activation of the polyol pathway seems to be an early event in both experimental [8] and human diabetic polyneuropathy [1] since increased sorbitol content is usually not found in chronically diabetic human nerve [9]. On the other hand, abnormalities in the expression of certain neurotrophic factors [10] and perturbed calcium metabolism [11] implicated in the pathogenesis of diabetic neuropathy seem to evolve more slowly and only become evident after several weeks or months of diabetes in the rat. This suggests a sequential and multistep series of pathogenetic events in diabetic neuropathy.

Hyperglycaemia seems to be the common and an important culprit in the initiation of the various metabolic aberrations underlying diabetic neuropathy. This notion was confirmed by the results of the Dia- betes Control and Complications Trial showing a $60 \%$ reduction in clinical neuropathy in Type I diabetic patients subjected to intensive insulin treatment for 5 years [12]. As intensive glycaemic control does not completely prevent neuropathy hyperglycaemia is probably not the only initiating metabolic abnormality responsible for diabetic neuropathy. Recent studies of the neuropathies occurring in Type I and Type II diabetic patients and animal models $[5,13]$ suggest that insulin or $\mathrm{C}$ peptide deficiencies or both as such contribute to the generally more severe diabetic neuropathy in Type I compared with that of Type II diabetes [14-16] (Fig.1). Furthermore, only $50 \%$ of diabetic subjects develop clinically overt diabetic neuropathy [3] which strongly suggests susceptibility genes exist that predispose to the development of clinically overt diabetic neuropathy. The exploration of this possibility is, however, in its infancy for chronic complications of diabetes $[17,18]$ and is yet to start for diabetic neuropathy.

Hence, as more data accumulate about the mechanisms of the evolution of this common complication of diabetes, we are facing an increasingly complex, multifaceted disease process.

In this review we will first describe the structural changes in different models of experimental diabetes and point out their differences particularly between Type I and Type II diabetes and how they relate to human diabetic neuropathy. We will also emphasise how various structural changes relate to underlying metabolic and molecular abnormalities and the extent to which structural changes possibly account for functional abnormalities.

In the second part various pathogenetic mechanisms will be dealt with in the sequence in which they seem to evolve during the clinical course of dis- 
Table 1. Comparison of functional and structural abnormalities in Type I and Type II diabetic animal models

\begin{tabular}{|c|c|c|c|c|}
\hline & \multicolumn{2}{|c|}{ Type I diabetes } & \multicolumn{2}{|c|}{ Type II diabetes } \\
\hline & STZ rat & $\mathrm{BB} / \mathrm{W}$ rat & $d b / d b$ mouse & $\mathrm{BB} / \mathrm{Z}^{\mathrm{DR}}$ rat \\
\hline Nerve conduction velocity deficit & +++ & +++ & + & + \\
\hline Axoglial disjunction & ++ & +++ & - & - \\
\hline Paranodal demyel. & ++ & +++ & + & + \\
\hline Segmental demyel. & + & + & ++ & ++ \\
\hline Wallerian degeneration & + & + & ++ & ++ \\
\hline
\end{tabular}

$+=$ mild $;++=$ moderate $;+++=$ severe $;-=$ absent demyel. $=$ demyelination

ease. Again we will attempt to emphasise how these affect nerve function and structure (Fig.1).

These data have almost exclusively been obtained from experimental studies but will as far as possible be compared with human diabetic neuropathy.

\section{Pathology of experimental diabetic neuropathy}

Various experimental diabetic models have been used in the study of the structural changes in peripheral nerve $[5,19,20]$. They have shown varied results possibly because Type I and Type II animal models tend to exhibit different structural changes [5, 21]. Furthermore, the age at which diabetes is induced in inducible rat models appears to affect the structural development of the neuropathy [20]. The most commonly used experimental model, the streptozotocin (STZ)-induced diabetic rat, is regarded as being a Type I model $[19,20]$ despite not requiring insulin supplementation for its survival and being confounded by severe emaciation. The STZ rat model has early functional and biochemical abnormalities similar to those in human diabetic neuropathy [22]. These will be described later in this review. In contrast to the profound biochemical and functional abnormalities, morphological changes are mild in the peripheral nerve in the STZ rat which even after extended periods fails to show apparent fibre loss or pronounced nerve fibre degeneration [22] (Table 1). Detailed morphometric examinations of peripheral nerve in the STZ rat have, however, shown reproducible changes $[21,23]$ such as reduction in fibre size with a proximo-distal gradient $[24,25]$. Teased fibre examinations have shown nodal swelling, paranodal and segmental demyelination in a small percentage of fibres in rats diabetic for $8-12$ months [24, 26, 27]. Ultrastructural examinations have also shown paranodal axo-glial disruption preceding paranodal demyelination [26] (Table 1). It has been suggested that axonal atrophy in the STZ rat is due to osmotic shrinkage [28] or retardation of normal axonal maturation [29]. These explanations are unlikely because there is no condensation of axoplasmic organelles which would be expected with osmotic shrinkage of the axon [5].
A maturational defect in axonal growth is also unlikely since treatment with aldose reductase inhibitors (ARIs) or vasoactive agents which shows no effects on body growth restores axonal size [27, 30]. The characteristic axonal atrophy is already present in distal nerves after 8 weeks of STZ diabetes whereas proximal nerve fibres show expanded axons [25], reflecting a progressive defect in axonal transport of neurofilaments. As the neuropathy progresses proximal axons also become atrophic [24], suggesting a later occurring superimposed defect in the synthesis of neuroskeletal proteins. These findings coincide with the emergence of the defects in the availability of nerve growth factor (NGF) and IGF-1 both of which are necessary for the synthetic integrity of structural proteins in the cell somata $[31,32]$. In this context note that neural hypoxia, which has been invoked as an important pathogenetic factor [30], does not induce pronounced slowing of the slow component of axonal transport [33] and is therefore not likely to be responsible for the early distal axonal atrophy characteristic of the neuropathy in the STZ rat.

Distal axonal atrophy and cytoskeletal abnormalities are also seen in autonomic nerves, in which preganglionic and post-ganglionic fibres undergo degeneration and dystrophic changes [34]. These abnormalities possibly reflect a defect in the turnaround mechanisms of axonal transport. Structural examinations of the endoneurial vasculature has not been undertaken in a systematic fashion although it has been reported that microvascular densities increase after long-term treatment with evening primrose oil (containing $\gamma$-linoleic acid (GLA), dihomo GLA and dilinolein-mono GLA) [35]. It has been claimed that there is a reduction in the number of anterior horn motor neurons in STZ diabetes [36] and that dorsal root ganglion cells undergo an $18 \%$ loss in perikaryal volume [37]. Increased vacuolation of dorsal root ganglion cells has also been noted in rats with longstanding STZ diabetes [38]. These changes may reflect impaired protection against apoptosis in diabetes, mediated by decreased expressions of neurotrophic factors, particularly IGF-1 [39].

In contrast to the STZ rat, the spontaneously diabetic $\mathrm{BB} / \mathrm{W}$ rat [40] develops severe structural chan- 
ges in both somatic sensory and motor nerves and autonomic peripheral nerves [41-42] (Table 1) as well as in sensory central nerve tracts [43]. The diabetes in this model occurs spontaneously and rapidly around the age of 75 days due to an immune-mediated total destruction of pancreatic beta cells [40] with complete lack of insulin and $\mathrm{C}$ peptide. Hence, these animals require daily supplementation of insulin to survive. We have used this model extensively in our laboratory because it probably represents the best rodent model of human Type I diabetes.

The acute onset of diabetes is accompanied by an abrupt $20 \%$ decrease in nerve conduction velocity and evoked potential amplitudes [44], which subsequently level off until approximately 4 months duration of diabetes when there is a further progressive decline in nerve conduction velocity (NCV) [41, 44]. This late progressive decline in NCV coincides with progressive disruption of the paranodal Schwann cell-axon contacts (axo-glial disjunction), which constitute the paranodal ion-channel barrier [44] (Table 1). The early functional changes are reversible after insulin, ARI, or myo-inositol treatments [45-47]. They correlate with morphometrically detectable nodal swellings $[45,47]$ which are associated with intra-axonal $\left[\mathrm{Na}^{+}\right]$accumulation secondary to increased inactivation of nodal sodium channels and the early $\mathrm{Na}^{+} / \mathrm{K}^{+}$-ATPase defect $[47,48]$. These structural and metabolic abnormalities are also rapidly reversible after correction of hyperglycaemia or the polyol pathway or neural myo-inositol depletion [45-47].

The progressive disruption of the paranodal apparatus is associated with decreased nodal sodium permeability, probably related to redistribution of nodal sodium channels to the internodal axolemma [49]. Interestingly this paranodal structural defect is also associated with a similar redistribution of Schwann cell glucose transporter (GLUT)-1 and axonal GLUT-3 [50]. The functional consequence of these abnormalities is a slowed increase in the initial $\mathrm{Na}^{+}$current of the evoked potential, which eventually leads to a conduction block resulting in decreased NCV. The specific molecular events underlying these paranodal changes, characteristic of both Type I human and rodent neuropathy are not understood. Preliminary studies have shown imbalances in the expression of various cell-adhesive molecules as well as polysialic acid and E-cadherin [51]. It is not known whether the activity and signal transduction of these molecules are regulated by the co-localised, high affinity insulin receptor.

Apart from axo-glial disjunction and paranodal demyelination, the neuropathy in the $\mathrm{BB} / \mathrm{W}$ rat is characterised by progressive distal axonal atrophy of both myelinated and unmyelinated fibres similar to, but more severe than, that in the STZ rat $[41,52]$. By a year of diabetes there is approximately a $50 \%$ loss of myelinated fibres in the sural nerve [41]. Hence, these changes are similar to those in Type I human diabetic neuropathy [13]. In addition to the peripheral nerve changes, the $\mathrm{BB} / \mathrm{W}$ rat shows progressive distal axonal atrophy and fibre loss in the dorsal columns of the spinal cord [53], underpinning a true central-peripheral dying back phenomenon characterising diabetic neuropathy.

Axonal atrophy and degeneration occur in both myelinated and unmyelinated fibres of the vagus nerve accompanied by a progressive decline in RR interval variability [54]. Similar changes occur in the penile and distal myenteric parasympathetic nerves [42] and in the nerves innervating the urinary bladder [55]. In these autonomic circuits notably the sensory afferent limb is consistently affected first and progressively more severely involved compared with the efferent parasympathetic limb [55].

Examination of the optic nerve in the $\mathrm{BB} / \mathrm{W}$ rat has shown axonal atrophy and paranodal axo-glial disjunction similar to that seen in somatic peripheral nerve [56], although they occur at a slower pace than in peripheral nerves. These changes which are responsive to ARI treatment correlate with prolonged latencies of visual evoked potentials [56]. Mononeuropathic changes resulting from endoneurial vascular occlusions by platelets, probably secondary to abnormal prostacyclin metabolism, have been reported in the $\mathrm{BB} / \mathrm{W}$ rat [57].

As in the STZ rat, nerve regeneration is impaired in the $\mathrm{BB} / \mathrm{W}$ rat [58], which is associated with perturbations of neurotrophic factors such as NGF and IGF-1 and their receptors [59] (Fig.1). Note that although regeneration is highly promoted by ARI treatment in previously axotomised $\mathrm{BB} / \mathrm{W}$ rats [58], the increased number of regenerated fibres do not attain functional and structural maturity even 220 days after axotomy [59]. As in non-treated diabetic BB/W rats, those treated with ARI fail to show maturation of the paranodal apparatus of regenerated fibres, which most likely accounts for the failure to attain normal NCVs and amplitudes in regenerated fibres [58].

From the above it is apparent that the spontaneously diabetic $\mathrm{BB} / \mathrm{W}$ rat develops a spectrum of neuropathic syndromes which generally resemble those that develop in Type I human diabetic neuropathy [13]. Although, underlying metabolic abnormalities are similar to those of the STZ rat, its advantage lies in the development of structural changes similar to those in human disease, which hence can be correlated with functional and metabolic aberrations as outlined above. The STZ rat by comparison can be regarded as in-between a Type I and Type II diabetic model since it is not insulin dependent but capable of producing sufficient insulin (and C peptide) for its survival.

Several Type II diabetic models have been investigated. The $d b / d b$ mouse shows full penetrance of a 
Type II hyperinsulinaemic diabetic syndrome associated with obesity. Nerve conduction velocity decreases with onset of diabetes and is reversed by sufficient insulin treatment [60]. In contrast to other diabetic rodent models, in the $d b / d b$ mouse motor NCV appears to be more consistently affected than sensory NCV [61].

Structurally this model shows a mild but progressive axonal atrophy but no pronounced fibre loss or paranodal changes [60,62] (Table 1). The fibre atrophy seen in this model was suggested [62] to be due to a maturational defect as reflected by decreased long bone growth. These data could not, however, be replicated by others [60]. Endoneurial capillaries in the $d b /$ $d b$ mouse are normal in appearance, although thickening and duplication of endothelial basal laminae have been noted. The fatty Wistar diabetic rat (WKY/Ncp) has proved a useful model for Type II diabetes [63, 64]. It shows decreased motor NCV and structural changes occurring at 10-11 months of diabetes consisting of axonal degeneration, paranodal and segmental demyelination [63]. The WBN/Kob rat is a selectively inbred spontaneously diabetic model that develops chronic pancreatitis and non-insulin requiring diabetes. Structural studies of this model have shown mild axonal atrophy, segmental demyelination and pronounced endoneurial vascular changes [65].

A relatively new model with spontaneous onset of Type II diabetes, the obese $\mathrm{BB} / \mathrm{Z}^{\mathrm{DR}}$ rat [66], shows mild deficits in NCV and progressive mild axonal atrophy but no nerve fibre loss even after 14 months of diabetes. Instead, it shows relatively strong segmental demyelination and Wallerian degeneration compared with the Type I diabetic BB/W rat (Table 1). This, like all of the Type II rodent animal models, fails to show paranodal changes or axo-glial disjunction which is in keeping with the lack of this structural abnormality in Type II human diabetic neuropathy [13]. It therefore seems to set Type I and Type II diabetic neuropathies apart not only neuropathologically but also translating into differences in NCV.

Thus, several animal models representing either Type I or Type II diabetes develop neuropathologic changes. Despite similar hyperglycaemic levels, differences exist in their expression of morphologic changes. Type I BB/W rats show severe axonal and paranodal changes, less expressed in Type II models which instead tend to show more pronounced demyelinating and vascular changes. The commonly used STZ rat shows structural changes between those of the Type I and Type II models.

\section{Pathogenetic mechanisms}

The polyol pathway and $\mathrm{Na}^{+} / \mathrm{K}^{+}$-ATPase. An early and extensively investigated metabolic pathway in diabetic neuropathy is the increased activation of the polyol pathway in which excessive glucose is shunted by the high $\mathrm{K}_{\mathrm{m}}$ aldose reductase to form sorbitol and fructose [6]. Accumulation of the organic osmolyte sorbitol results in compensatory depletions of other osmolytes such as myo-inositol and taurine [67]. Myo-inositol depletion is by pertubation of phosphoinositide metabolism [6], in part responsible for the concommitant reduction in $\mathrm{Na}^{+} / \mathrm{K}^{+}$-ATPase activity, which appears to be important in explaining the early reversible nerve conduction defect in experimental diabetes $[68,69]$. It has been suggested that impaired activation of neural protein kinase $\mathrm{C}$ by diminished phosphoinositide derived diacylglycerols mediates the effect of myo-inositol depletion on $\mathrm{Na}^{+} / \mathrm{K}^{+}$-ATPase activity [70,71]. It is notable that in galactosaemic rats or mice who develop a diabetes-like neuropathy, the NCV defect is associated with an increase in $\mathrm{Na}^{+} / \mathrm{K}^{+}$-ATPase [72, 73], suggesting that in these models factors other than impaired $\mathrm{Na}^{+} / \mathrm{K}^{+}$-ATPase activity underlie the functional defect. Alternatively, increased $\mathrm{Na}^{+} / \mathrm{K}^{+}$-ATPase in galactosaemic neuropathy may represent endothelial $\mathrm{Na}^{+} / \mathrm{K}^{+}$-ATPase activity rather than neuronal.

Furthermore protein kinase $\mathrm{C}$ inhibitors have an unexpected effect on the hyperecitability of nociceptive C-fibres in STZ diabetic rats [74], suggesting that protein kinase $\mathrm{C}$ isoforms are affected differently in diabetic peripheral nerve. $\mathrm{Na}^{+} / \mathrm{K}^{+}$-ATPase activity in diabetic rats can be affected through several perturbed metabolic pathways some of which are associated with activation of the polyol pathway such as nitric oxide synthesis [6], pseudohypoxia [75] or prostacyclin deficiency [76, 77]. This explains not only the effects of aldose reductase inhibition and myo-inositol supplementation on $\mathrm{Na}^{+} / \mathrm{K}^{+}$-ATPase and NCV in experimental diabetic neuropathy but also those of prostacyclin analogues or their precursors [77], acetyl-L-carnitine [8,78] or C peptide [15].

The polyol pathway is also linked to oxidative stress, since this is considerably diminished in sciatic nerve and lens by ARI treatment of diabetic or rats fed with galactose [79, 80] (Fig. 1). Aldose reductase of the polyol pathway requires NADPH as a cofactor as does the glutathion redox cycle [30] and nitric oxide synthase in the arginine $\rightarrow$ citrulline + nitric oxide pathway [6]. Thus, when the polyol pathway is activated, a competitive NADPH deficit will impact on the recycling of glutathione (GSH) from oxidised glutathion (GSSG) (Fig. 2) and the synthesis of nitric oxide (Fig. 3). It has been shown that oxidation of sorbitol to fructose by sorbitol dehydrogenase increases the ratio of NADH:NAD ${ }^{+}$, resulting in an increased lactate:pyruvate ratio and "pseudohypoxia" [75] and that inhibition of sorbitol dehydrogenase improves vascular and neural dysfunction [81]. These results have not, however, been reproduced by others [82, 83]. Treatment with acetyl-L-carnitine, which has no effect on the polyol pathway, has been shown to cor- 


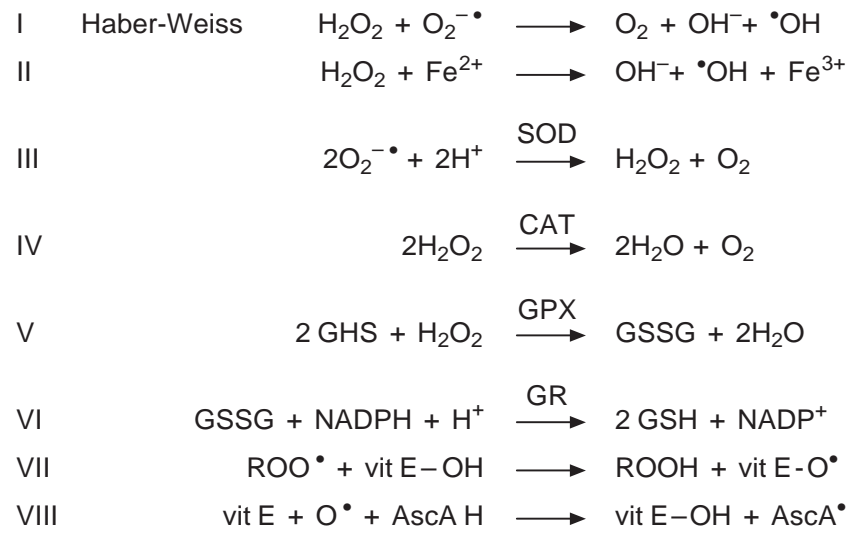

Fig. 2. Sequence of the formation of hydroxyl radicals $\left({ }^{\circ} \mathrm{OH}\right)$ and the ROS scavenging system. In the Haber-Weiss reaction (I) superoxide $\mathrm{O}_{2}^{-} \cdot$ is reduced by hydrogen peroxide, $\mathrm{H}_{2} \mathrm{O}_{2}$, to form hydroxyl radicals $\left({ }^{\circ} \mathrm{OH}\right)$. This reaction is catalysed by transition metal ions, mainly iron or copper, the Fenton reaction (II). Superoxide $\mathrm{O}_{2}^{-}$is reduced to $\mathrm{H}_{2} \mathrm{O}_{2}$ in the presence of superoxide dismutase (SOD) (III), which is further reduced to water and molecular oxygen in the presence of catalase (CAT)(IV). Hydrogen peroxide, $\mathrm{H}_{2} \mathrm{O}_{2}$ is reduced by reduced glutathione $(\mathrm{GSH})$ in the presence of glutathione peroxidase $(\mathrm{GPX})(\mathrm{V})$. The oxidised glutathione (GSSG) so formed is reduced back to reduced glutathione in the presence of glutathione reductase (GR) and NADPH (VI). Peroxyl radicals $\left(\mathrm{ROO}^{\bullet}\right.$ ) are reduced by vitamin E (vit E-OH) (VII), and oxidised vitamin (Vit $\mathrm{E}_{-} \mathrm{O}^{\bullet}$ ) is reduced, probably by ascorbic acid (AseAH)

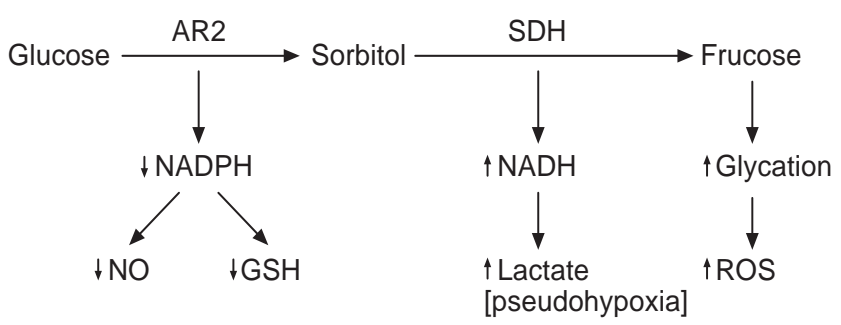

Fig.3. Relations between the activated polyol pathway, NO production, reduced glutathione (GSH) availability, pseudohypoxia, non-enzymatic glycation and ROS production

rect neural $\mathrm{Na}^{+} / \mathrm{K}^{+}$-ATPase [8, 84], blood flow [85, 86], NCV as well as vasoactive prostaglandins [8]. An additional mechanism by which $\mathrm{Na}^{+} / \mathrm{K}^{+}$-ATPase activity is impaired in diabetic nerve is by $\mathrm{C}$ peptide or insulin deficiency or both because C-peptide treatment, which does not influence hyperglycaemia, returns $\mathrm{Na}^{+} / \mathrm{K}^{+}$-ATPase and NCV to normal in diabetic nerve $[14,15]$ (Fig.1). Whether this effect by $\mathrm{C}$ peptide is due to activation of the insulin receptor signalling pathway intermediaries or alternate pathways is not yet known [87].

These findings suggest that multiple, not necessarily related to the polyol pathway, metabolic aberrations are responsible for decreased neural $\mathrm{Na}^{+} / \mathrm{K}^{+}$-ATPase. The absence of detectable demyelination or nerve fibre degeneration in association with the rapid NCV slowing in acutely diabetic rats $[41,45]$, suggest a biochemical or biophysical mechanism or both. Direct measurement of reduced nerve $\mathrm{Na}^{+} / \mathrm{K}^{+}$-ATPase activity associated with decreased $\mathrm{NCV}$ as well as their corrections by dietary myo-inositol [45, 69], ARI treatment [69] acetyl-L-carnitine [8] or C-peptide supplementation $[14,15]$ suggests a close link. This is further supported by voltage clamp studies in acute diabetic neuropathy in the diabetic $\mathrm{BB} / \mathrm{W}$ rat documenting a corresponding reduction in the resting axolemmal membrane $\mathrm{Na}^{+}$potential, increased inactivation of nodal $\mathrm{Na}^{+}$-channels and a multifold increase in intraaxonal $\left[\mathrm{Na}^{+}\right][47-48]$. These bioelectrical abnormalities are associated with morphometrically detectable nodal axonal swellings, which are reversible after myo-inositol supplementation or ARI treatment [45-47]. It therefore appears that the first step of the polyol-pathway activation is important for the acute effects of hyperglycaemia in diabetic nerve.

In the galactosaemic rat model, galactose is converted to galactitol by aldose reductase, which is, however, a poor substrate for sorbitol dehydrogenase and is therefore not metabolised further by the second step of the pathway. Importantly, galactosaemia gives rise to ARI-preventable abnormalities similar to those of diabetes such as NCV slowing, vascular dysfunction, impaired regenerative capacity, nodal axonal swelling and paranodal axo-glial disjunction $[88,89]$. Similar results were obtained from feeding galactose to mice transgenic for the human aldose reductase gene, who develop slowed NCV and severe nerve fibre atrophy [90]. Composite $\mathrm{Na}^{+} / \mathrm{K}^{+}$-ATPase activity in peripheral nerve is, however, increased in galactosaemic animals but returns to normal after treatment with ARI [73].

From experimental diabetic neuropathy it is therefore apparent that the activation of the polyol pathway by glucose plays an important part in the early pathophysiology of this disorder not only by excerting effects on sorbitol, myo-inositol and $\mathrm{Na}^{+} / \mathrm{K}^{+}$-ATPase metabolism but also through secondary mechanisms affecting generation of reactive oxygen species, perturbing nitric oxide synthesis and promoting nonenzymatic glycation (Figs. 1,3) [6,30].

It should, however, be emphasised that increased polyol-pathway activity does not appear to be an essential pathogenetic mechanism in diabetic neuropathy, since diabetic mice accumulate only low polyol concentrations in sciatic nerve and still develop neuropathy [91]. Recent studies on the $\mathrm{BB} / \mathrm{W}$ rat suggest that the accumulation of sorbitol and associated myoinositol depletion diminish as the neuropathy progresses and that secondary or other metabolic mechanisms or both become more prominent [8]. Whether this is also true for human diabetic neuropathy is not known but, if so, it would in part explain the generally disappointing results from clinical neuropathy trials using aldose reductase inhibitors [92]. 
The role of oxidative stress and decreased blood flow. Diabetes causes increased oxidative stress which can be defined as a higher production of reactive oxygen species (ROS) as well as an impaired endogenous capacity to scavenge free radicals [7, 93, 94]. Increased production of ROS leads to increased peroxidation of lipid membranes, proteins and DNA with important consequences for cell function and structure. A notable target for increased pro-oxidant activity in diabetes is the vascular system in part explaining the increased propensity for atherogenesis and cardiovascular disease [30]. In the microvascular complications of diabetes, oxidative stress affects endothelial cell function and vascular reactivity, contributing to impaired blood flow and oxygenation in peripheral nerve (Fig. 1). The mechanisms underlying the increased presence of ROS and impaired activity of antioxidant factors in diabetes are multifold and not completely understood [93, 94].

Molecular oxygen becomes toxic when reduced products like superoxide, $\mathrm{O}_{2}^{-\bullet}$, hydrogen peroxide and the hydroxyl radical ${ }^{\circ} \mathrm{OH}$ are formed through the Harber-Weiss reaction (Fig. 2). Further contributions are provided by autoxidation of molecules like glucose, ascorbic acid, thiols and catecholamines enhanced by transition metal ions, particularly iron and copper [95].

Increased production of ROS is associated with ischaemia-reperfusion effects induced by the conversion of xanthine to uric acid by xanthine oxidase [96]. Reactive oxygen species are generated from the electron transport chains in mitochrondria and by activated phagocytes.

Polyunsaturated fatty acids are particularly vulnerable to free radical damage because the fatty acid radical adds oxygen to form a peroxyl radical which by oxidising further fatty acids perpetuates the process [30]. Another particular target for ROS is the glycolytic and mitochrondrial phosphorylation of ADP with profound effects on cell energy metabolism [97].

Among the free radical defence mechanisms, superoxide dismutase (SOD) scavenges superoxide and is located in cytosol and mitochrondria. The hydrogen peroxide that is formed is converted to water and molecular oxygen (Fig. 2). Glutathione peroxidase is an enzyme that eliminates both lipid hydroperoxides and hydrogen peroxide. Most free radical scavengers, however, are compounds which react with free radicals. An important compound is $\alpha$-tocopherol (vitamin E) that reacts with lipid peroxyl and hydroxyl radicals (Fig. 2). It interrupts the self-perpetuating chain reaction of lipid peroxidation. Other lipid soluble antioxidants are ubiquinone and cartenoids. Water soluble antioxidants include ascorbic acid, cystine and uric acid.

Oxidative stress causes a series of changes in endothelial cell function and gene expression in diabetes.
The vascular renin-angiotensin system is up regulated in several vascular systems including vasa nervorum [98, 99]. Circulating plasma angiotensin converting enzyme (ACE) activity is increased in diabetic rats and patients [100]. This increase is prevented in STZ rats by the antioxidant probucol [101]. Another vasogenic factor increased by oxidative stress is endothelin- 1 , probably by nuclear factor- $x \mathrm{~B}(\mathrm{NF}-\varkappa \mathrm{B})$ [102].

Both endothelin- 1 and angiotensin II are potent vasoconstrictors and therefore probably contributors to reduced peripheral nerve blood flow in diabetes.

Endothelin-1 antagonists, such as the $\mathrm{ET}_{\mathrm{A}}$ receptor antagonists BQ123 and BM5 182874, restore the decreased blood flow and NCV in streptozotocin STZ rats, whereas the $\mathrm{ET}_{\mathrm{A}} / \mathrm{ET}_{\mathrm{B}}$ antagonist basentan has a lesser effect $[103,104]$. This is probably because stimulation of the $\mathrm{ET}_{\mathrm{B}}$ receptor releases nitric oxide (NO) and prostacyclin, causing vasodilation which offsets the $\mathrm{ET}_{\mathrm{A}}$-mediated vasoconstriction [103]. Activation of NF $\mathrm{BB}$ also increases adhesion of leucocytes to endothelial cells and therefore contribute to increased incidence of thrombosis in diabetes [105]. $\alpha$ Tocopherol and probucol have inhibitory effects on leucocyte adhesion [106].

Reduced nutritive blood flow resulting in endoneurial hypoxia has been implicated as an important and early pathogenetic factor in diabetic neuropathy in both patients and animal models [7, 107]. This notion is strongly supported by experimental data, since blockade of the renin-angiotensin system with either ACE-inhibitors or angiotensin II $\mathrm{AT}_{1}$ receptor antagonists reduces impaired blood-flow, endoneurial oxygenation and NCV in STZ diabetic rats [98, 99, 108]. The same regimen also prevents the increased resistance to ischaemic conduction failure and restores the blunted regenerative capacity of nerve fibres to normal [99]. In addition $\mathrm{ACE}$ and $\mathrm{AT}_{1}$ inhibition partially protects against deficits in NO-mediated vessel relaxation and vessel hypertrophy [109].

Oxidative stress affects endothelium-dependent vessel relaxation which is evident even in acute hyperglycaemia. Peroxynitrite formed from the neutralising effect of superoxide on NO has a toxic effect on endothelial cells [110]. The reduction in acetylcholine mediated endothelium-dependent relaxation of aortic rings incubated in high glucose can be partially prevented by the antioxidant probucol or by SOD $[111,112]$.

Likewise impaired endothelium-dependent relaxation of corpus cavernosum, coronary vessels and aorta can be prevented by a variety of radical scavengers, such as $\alpha$-tocopherol, dimethylthiourea and acetyl cysteine, which also correct impaired peripheral nerve blood flow and NCV [113]. Acetyl cysteine and $\alpha$-tocopherol have, in addition, a protective effect on axonal atrophy and blunted nerve fibre regeneration characteristic of diabetic neuropathy [114, 115]. 


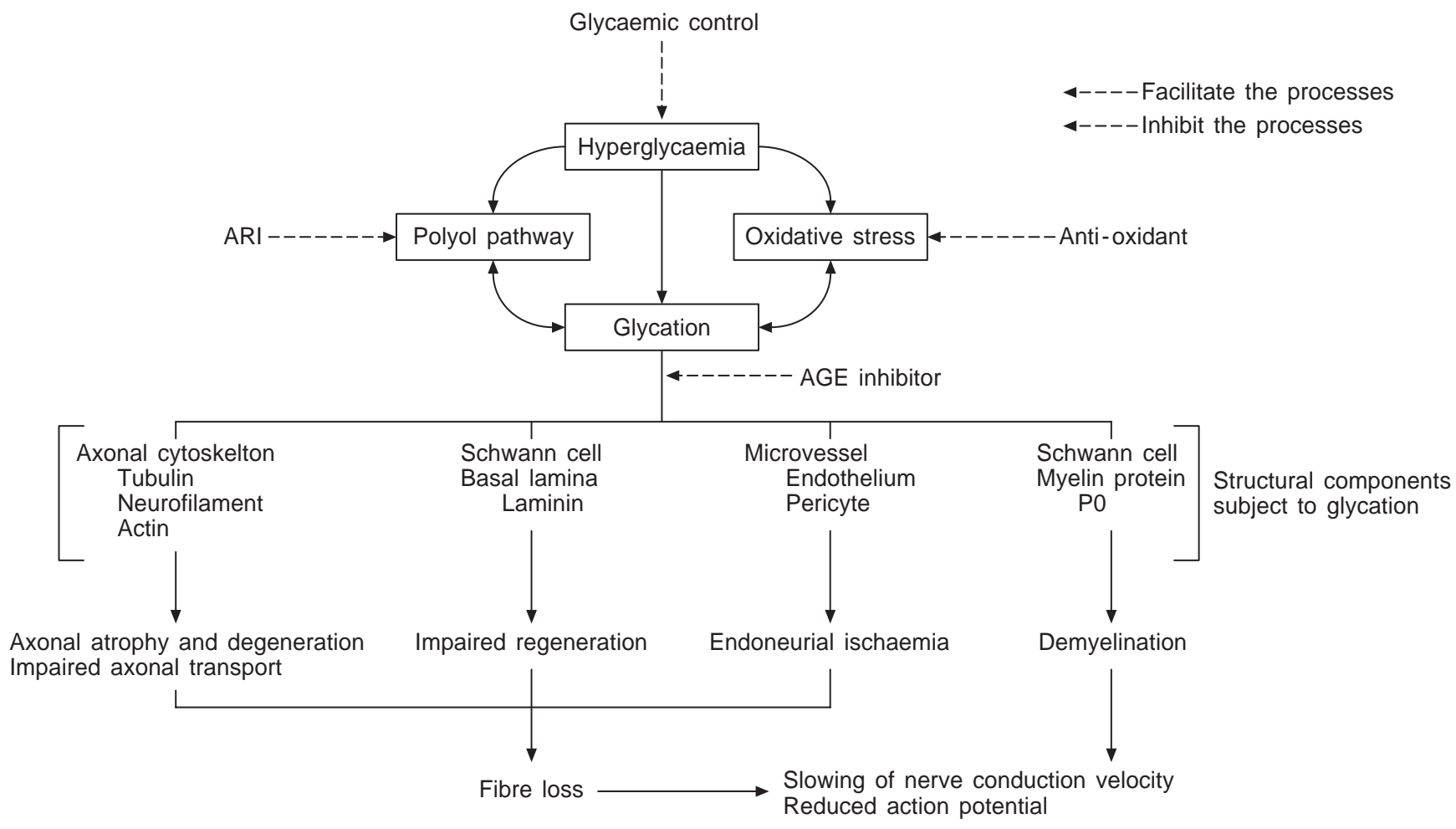

Fig. 4. Pathogenetic mechanisms possibly related to non-enzymatic glycation. Consequences of neuropathic changes developing as a result of non-enzymatic glycation of structural components are shown. Axonal cytoskeletal proteins such as tubulins, neurofilaments, and actin are subject to non-enzymatic glycation. Glycation of these structural proteins may contribute to impaired axonal transport, axonal atrophy and degeneration. Myelin proteins such as PO, myelin basic protein, and proteolipid protein are also subjected to glycation and may be scavenged by macrophages, possibly leading to segmental demyelination. Deposition of AGE's-proteins in Schwann cells may result in dysregulation of trophic support of nerve fibres and impaired synthesis of myelin proteins. Modification of laminin by glycation may impair fibre regeneration. Localisation of glycated proteins such as CML in endoneurial microvessels possibly relate to microvascular changes such as thickened vessel walls and narrowed vascular lumina through cellular responses of both endothelial cells and pericytes to increased oxidative stress

Furthermore, $\alpha$-lipoic acid has a preventive effect on the impaired function of nitrergic vasodilator fibres innervating corpus cavernosum, suggesting a potential treatment for diabetes associated impotence [113].

The contribution by autoxidation of monosaccharides and advanced glycation events to ROS production, catalysed by transition metal ions, is important in peripheral nerve. Treatment with transition metal chelators rapidly corrects nerve blood flow and NCV in diabetic rats and rats fed with galactose [30].

Hence, impaired nutritive blood flow in diabetic nerve is an early event that undoubtedly contributes to the pathogenesis of diabetic neuropathy $[30,116]$.
Several lines of evidence implicate oxidative stress, induced by increased production of ROS as well as impaired endogenous free radical scavenging capacity, as major causative factors.

The role of non-enzymatic glycation in diabetic neuropathy. In the process of non-enzymatic glycation, reducing sugars such as glucose, fructose or galactose initially react with free amino groups of proteins, lipids or nucleic acids to form the early reversible products such as Schiff bases and ketamines or Amadori adducts. In addition autoxidative glycosylation takes place through the Wolff pathway forming glycoxidation products [117, 118]. Critical intermediaries in the formation of advanced glycation end products (AGEs) are 3-deoxyglucosone (3DG) from fructoselysine and glyoxal and methylglyoxal (MGO) from either Amadori compounds, Schiff base intermediaries or direct oxidation of sugars $[119,120]$. With time these products undergo chemical rearrangement, dehydration and fragmentation reactions and crosslinking to form irreversible AGEs. In vivo, AGEs accumulate ubiquitously in the body including peripheral and central nervous systems. A variety of neurodegenerative disorders including Alzheimer's disease, Parkinson disease, diffuse Lewy body disease and amyotrophic lateral sclerosis show increased non-enzymatic glycation of tau protein, the constituents of Lewy bodies as well as $\mathrm{Cu}^{++}, \mathrm{Zn}^{++}$-superoxide dismutase contributing to cell death by the generation of oxidative stress.

It has been shown that the glycation process is enhanced in peripheral nerve in both diabetic patients 


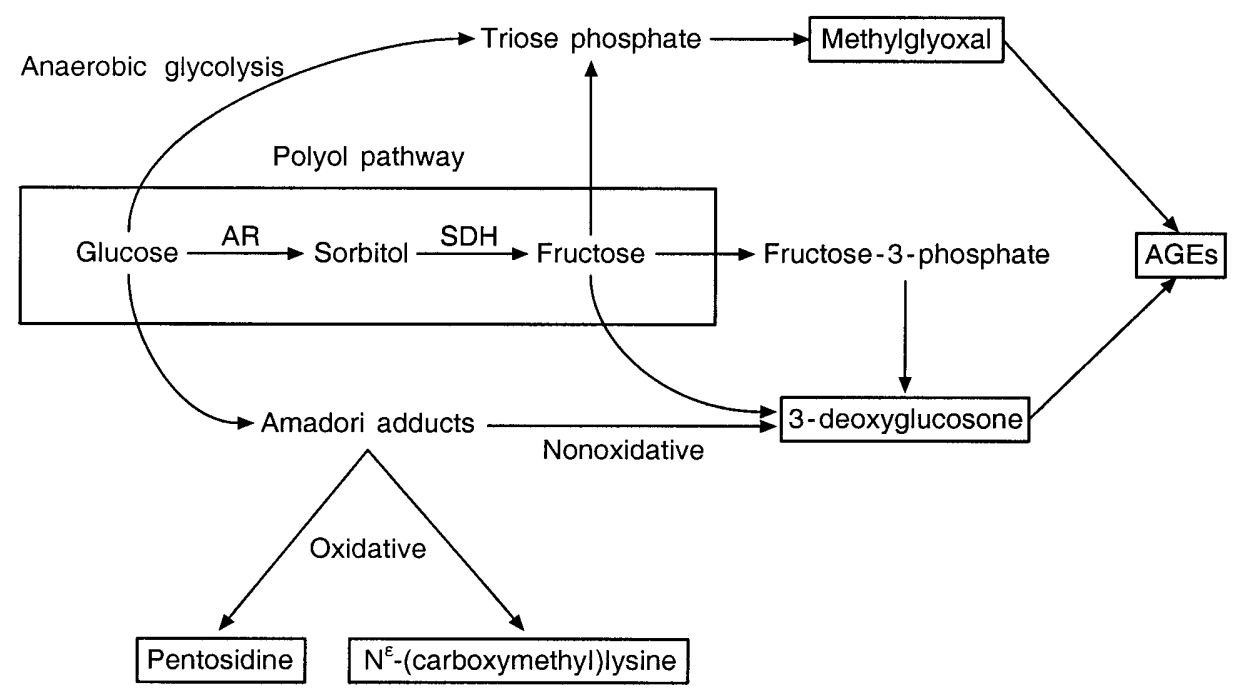

Fig.5. Relations between polyol pathway and non-enzymatic glycation. 3-Deoxyglucosone is induced by amino groups of proteins reacting with fructose and fructose-3-phosphate. Fructose-3-phosphate is produced by phosphokinase from fructose. Methylglyoxal is formed by amino groups reacting with triose phosphate. Triose phosphate is produced during anaerobic glycolysis and by the reaction of fructokinase with fructose. Reactive oxygen species are not primarily involved in the formation of either 3DG or MGO. On the other hand, both $N^{\mathrm{e}}$-[carboxymethyl] lysine and pentosidine are oxidation products initiated by the reaction of free lysine with glucose. AR, aldose reductase; SDH, Sorbitol dehydrogenase

and animals [121, 122]. Studies in diabetic rats have shown that myelin components such as $\mathrm{P} 0$, myelin basic protein and proteolipid protein are subject to nonenzymatic glycation [122, 123] (Fig.4). It has been suggested that peripheral nerve myelin modified by AGEs becomes recognised and scavenged by macrophages via putative AGE-specific receptors [124]. Such interactions between peripheral nerve myelin and macrophages are likely to contribute to segmental demyelination in diabetes by digestion of myelin proteins (Fig. 1). Several axonal cytoskeletal proteins such as tubulin, neurofilament and actin also undergo glycation [125-127] (Fig.4). These axonal components have essential roles in the maintenance of axonal function and structure. Their modification by glycation causes alterations of axonal structures, slowed axonal transport, axonal atrophy and degeneration (Fig.1). Laminin, a major constituent of Schwann cell basal laminae, functions as a promotor and guidance for regenerating fibres. Glycated laminin (Fig. 4) loses its ability to promote nerve fibre regeneration, a phenomenon that probably contributes to impaired nerve fibre regeneration in diabetes [128].

Recent studies have indicated that not only glucose but also glucose-6-phosphate, products of the pentose phosphate pathway as well as trioses and fructose produced through the polyol pathway, participate in the generation of glycated proteins [129]. Fructose for instance is a much more potent glycator than glucose or galactose $[129,130]$. One of the major carbonyl adducts and a potent AGE precursor, 3DG, is formed directly from fructose [129] (Fig. 5). Crosslinking of proteins, which is the most characteristic feature of AGEs, is promoted by fructose. Fructose can be metabolised to fructose-3-phosphate and triose phosphate by phosphokinase and fructokinase, respectively. These metabolites become potential sources of 3DG and MGO (Fig.5) [131, 132] both of which are potent cross-links causing tissue damage through oxidative stress [133]. Hence these metabolites promote the formation of AGEs, which when involving structural neuronal proteins interfere with their polymerisation and normal function. On the other hand, it has been reported that the activity of sorbitol dehydrogenase, the second enzyme in the polyol pathway, is considerably suppressed by glycation [134]. It is therefore possible that excessive production of fructose deactivates sorbitol dehydrogenase through increased glycation, thereby preventing further production of fructose and subsequent accumulation of AGEs. In addition, intervention studies with ARIs in diabetic patients and animals have shown a pronounced reduction in the tissue concentrations of glycated proteins in aorta, lens and erythrocytes $[135,136]$. Although there are convincing data supporting a linkage between the polyol pathway and glycation in a variety of tissues, there is little showing this in nervous tissues. In the process of glycation and oxidation reactions glycoxidation products are formed such as $N^{\varepsilon}$-[carboxymethyl]-lysine (CML) and pentosidine which are considered markers for both glycative as well as oxidative stress (Fig. 5) [94]. Other than the oxidative stress induced directly by non-enzymatic glycation, oxidative stress is also enhanced by glycation and inactivation of $\mathrm{Cu}$ - 
Zn-superoxide dismutase [137]. Binding interactions between AGEs and their specific receptors such as the receptor for advanced glycation and end products has been suggested as being the source of oxidative stress, by depleting intracellular GSH and vitamin C, resulting in the induction of $\mathrm{NF}-x \mathrm{~B}$ in endothelial cells [138]. Antioxidants like lipoic acid can suppress the activation of $\mathrm{NF}-\varkappa \mathrm{B}$ in this process [138]. In a recent study [139], we showed that immunoreactive CML is localised to perineurial basal laminae, axons, Schwann cells and endoneurial microvessels in human peripheral nerve. The staining intensities were significantly increased in diabetic patients $(p<0.01)$ and correlated with myelinated fibre loss $(p<0.0005)$. Note, however, that CML is also formed during lipid peroxidation reactions. It has been shown [140] that aminoguanidine (AG) inhibits the formation of AGEs in aortic collagen in diabetic rats. Numerous studies in rats have confirmed the beneficial effect of AG on the development of retinopathy, nephropathy and neuropathy. In particular, improvements in nerve conduction velocity and morphometric variables after long-term treatment with AG have been documented [141]. The beneficial effect of AG was not immediate but became appreciable only after a prolonged lag period. The mechanism by which AG exerts its effect is not fully clarified and has been a matter of some controversy [118]. It appears, however, that AG inhibits cross-linking but it is not clear whether this is due to entrapment of reactive carboxyl compounds or other glycoxidative intermediaries. It can therefore be said that AGEs and glycoxidation products participate in glycative and oxidative damage leading to cytotoxicity, cell injury and to weakened antioxidant defences. This cycle of events is not, however, brought about by AGEs alone but also by reaction products derived from lipid peroxidation.

Changed neurotrophism in diabetic neuropathy. Aberrations in the synthesis and availability of neurotrophins and neurotrophic factors or their receptors have been implicated in the pathogenesis of diabetic neuropathy $[10,142]$.

The neurotrophins, which regulate a variety of neuronal proteins, are synthesized by the neuronal target cells and delivered to the neuronal perikarya by retrograde axonal transport. Nerve growth factor is one of the most researched neurotrophins which also include neurotrophin 3 (NT-3), neurotrophin 4/5 (NT-4/5) and brain derived neurotrophic factor (BDNF). It is synthesized in the periphery by muscle and skin and is transported retrogradely to a subset of sensory neurons and sympathetic ganglia [143, 144]. Likewise BDNF and NT-3 are transported by retrograde transport to dorsal root ganglia and motor neurons in adult rats [144]. Retrogradely transported NGF binds to two receptors; the high affinity trkA and the low affinity p75-receptor. In diabetic rats there is reduced availability of NGF that possibly reflects both decreased synthesis as well as decreased axonal transport [31, 59, 145]. In addition the mRNA expression of trkA in dorsal root ganglia and that of p75 in sciatic nerve are down regulated in diabetic rats [59]. These changes do not occur suddenly but gradually and are established in rats that have had diabetes for 12 weeks [142, 146] (Fig. 1).

Nerve growth factor, other neurotrophins as well as IGF-1 are involved in the regulation of several neuronal proteins. Nerve growth factor regulates the synthesis of medium and low molecular weight neurofilaments, as shown by an increase in neurofilament mRNA in axotomised dorsal root ganglia after treatment with NGF $[32,147]$ a function that it shares with insulin [148]. As neurofilaments are the major structural determinants for the maintenance of axonal size [24], this implies that deficient neurotrophic factors in diabetic neuropathy are in part responsible for the characteristic axonal atrophy (Fig.1). Nerve growth factor also appears to regulate the synthesis of substance P [142]. It is believed that NGF exerts this action through the regulatory protein preprotachykinin-A which regulates transcription of substance $\mathrm{P}$.

After nerve injury, the synthesis of NGF in target tissues is taken over by Schwann cells and fibroblasts at the site of injury. This response is thought to be induced by early transforming gene responses, such as $c$-fos and c-jun [142]. The subsequent early "emergency" response in local NGF synthesis is believed to induce interleukin 1 release from recruited macrophages which in turn sustain a more long-lasting production of NGF by Schwann cells and probably fibroblasts [149]. In diabetic nerve both the immediate gene responses as well as the sustained local mRNA expressions of NGF and trk A are considerably perturbed, which contribute to the delayed initiation and decreased sustenance of nerve fibre regeneration in diabetes $[58,142]$. The perturbed regeneration is mediated by impaired induction of neurofilament and growth-associated protein 43 (GAP-43) synthesis [150]. Nerve growth factor has been used in clinical neuropathy trials with some success in improving thermal perception [151]. A drawback, however, is the mechanical and thermal hyperalgesia caused by subcutaneous injections, probably reflecting its nociceptive role through substance $\mathrm{P}$.

In addition to NGF, NT-3 might be a potentially useful neurotrophin in the treatment of the mainly sensory diabetic neuropathy. Improvement of sensory NCV in diabetic rats after treatment for 4 weeks with human recombinant NT-3 has been shown [142].

Apart from the neurotrophins, there are systemically circulating peptides, such as insulin-like growth factor-1 (IGF-1), insulin and C peptide that have neuroprotective effects on peripheral nerve. Insulin-like 
growth factor- 1 is synthesized predominantly in the liver but is also produced in Schwann cells of peripheral nerve, where it has autocrine and paracrine functions. In diabetes IGF-1 derived from both systemic and from peripheral nerve shows a progressive decline, which are established in the spontaneously diabetic $\mathrm{BB} / \mathrm{W}$ rat with a $6-8$ week duration of diabetes $[10,152]$.

Both insulin and $\mathrm{C}$ peptide become rapidly deficient in Type I diabetes, in contrast to Type II diabetes which may even show increased levels. This difference between the two types of diabetes, may explain why functional and structural neuropathy in Type I models is more severe than in Type II diabetic models [21]. Insulin-like growth factor-1, insulin and C peptide all have neurotrophic actions on sensory, autonomic and motor neurons $[14,153]$. It has been postulated that decreased insulin concentrations secondarily impair IGF-1 synthesis [10] (Fig. 1). The insulin and IGF-1 receptors (IR; IGF-1R) are structurally similar, both being comprised of $\alpha_{2} \beta_{2}$ heterotetramers, where the extracellular $\alpha$-subunits contain the ligand binding domains. The IGF-1R is present on peripheral nerve somata, neurites and Schwann cells, whereas the IR is localised to the paranodal Schwann cell and the node of Ranvier and endoneurial vessels. Recent studies from our laboratory have shown that $\mathrm{C}$ peptide enhances the insulin receptor activity [87]. It has also been shown that $\mathrm{C}$ peptide binds to a specific membrane receptor (Wahren, personal communication). Insulin-like growth factor-1 promotes the synthesis of the low molecular weight and medium molecular weight neurofilaments [48], whereas insulin promotes phosphorylation of neurofilaments, necessary for their polymerisation and exportation from the somata to the neurites [10]. Both insulin and IGF-1 increase $\alpha$ - and $\beta$-tubulin mRNA in vitro by stabilising their transcripts, a property they share with NGF $[148,154]$. Insulin growth factor-1 appears to have a more pronounced effect on $\beta$-tubulins. It has been shown that IGF-1 enhances growth cone motility by promoting reorganisation of actin and activation of focal adhesion proteins [155]. These data are likely to explain ARI-treated rats and humans $[46,58,92]$ showing an appreciable increase in nerve fibre regeneration, which in the $\mathrm{BB} / \mathrm{W}$ rat is associated with a sixfold up regulation of nerve IGF1 mRNA [59]. Insulinlike growth factor- 1 also has a protective effect on glucose induced apoptosis which appears to be mediated by activation of mitogen-activated protein kinases [156] (Fig.1).

Both insulin and $\mathrm{C}$ peptide have neuroprotective effects. Supplementation of C peptide in Type I diabetic rats has no effect on hyperglycaemia, but restores $\mathrm{Na}^{+} / \mathrm{K}^{+}$-ATPase to normal in both peripheral nerve [15] and renal tubule cells and NCV $[14,15]$, suggesting a mode of action different from that of insulin.
Therefore it appears that perturbations of various neurotrophic factors are of pathogenetic importance particularly in the development of structurally recognisable changes secondary to abnormalities in the synthesis of structural proteins. This is in keeping with the observation that changes in neurotrophic support do not occur suddenly but gradually as diabetic neuropathy progresses from a metabolic to a structural phase (Fig. 1).

Essential fatty acids. Production of vasoactive prostanoids is compromised in diabetes [30,157]. This is believed to be due to impaired desaturation particularly of the $\Delta-6$ step in their synthesis with subsequent deficits in the $\omega-6$ essential fatty acids. The depressed desaturation, particularly in the liver, is probably due to a combination of hyperglycaemia, hypoinsulinaemia and oxidative stress [158]. The consequences of the impaired $\Delta-6$ desaturation step are reduced tissue and plasma concentrations of $\gamma$-linoleic acid and arachidonic acid with impaired synthesis of cyclooxygenase products such as vasodilatory and antiplatelet aggregation prostaglandins [30]. These abnormalities lead to increased vascular tone and decreased endoneurial blood flow.

Synthesis of prostaglandins $\mathrm{PG}_{2}$ and $\mathrm{PGE}_{2}$ is reduced in sciatic nerve secondary to diminished arachidonic acid $[8,158]$. This deficit is overcome by treating diabetic rats with evening primrose oil, resulting in restoration of vasoactive prostaglandins and preventing decreased nerve blood flow, nerve hypoxia and impaired NCV [30, 159, 160] (Fig. 1). Longterm treatment with evening primrose oil also promotes endoneurial vascularisation in diabetic and galactosaemic rats $[161,162]$. These effects are blocked by cyclooxygenase inhibition underlining the importance of prostanoid synthesis for these effects [35]. These data support the notion that impairment of essential fatty acid synthesis in diabetes exerts its main effect on the endoneurial vasculature. These effects are, however, potentiated by increased blood flow secondary to the stimulatory effect of prostanoid synthesis on NO release.

Another aspect of abnormal fatty acid metabolism involves reduced plasma and tissue L-carnitine content in experimental diabetes [87, 163]. Treatment with L-carnitine prevents the development of diabetic neuropathy $[8,163]$.

In diabetic neuropathy acetyl-L-carnitine improves nerve regeneration and prevents structural and morphometric abnormalities [8]. The mechanisms by which L-carnitine acts are not fully clear but it appears to have several effects. It improves cellular energy metabolism by promoting mitochondrial transport of long-chain fatty acids for $\beta$-oxidation, it restores neural $\mathrm{Na}^{+} / \mathrm{K}^{+}$-ATPase, $\mathrm{NO}$ synthesis and prostaglandins to normal $[8,84]$, improves nerve blood flow [86] and may act as an antioxidant [85]. 
It is therefore evident that essential fatty acid metabolism perturbing vasoactive prostanoids have important pathogenetic functions in diabetic neuropathy. These mechanisms often act in concert with additional pathogenetic elements such as the polyol pathway and non-enzymatic glycation, with consequences for normal vessel function, although this is not the only target tissue.

\section{Conclusion}

Several animal models have proven to be useful for the study of diabetic neuropathy. It is apparent that diabetic neuropathy is a multifactorial disorder in which various metabolic abnormalities are interrelated but appear to occur sequentially during the clinical course of the disease. Moreover, it is also evident that the neuropathies accompanying Type I and Type II diabetes are different. The usually milder neuropathies in Type II models, despite similar degrees of hyperglycaemia, suggest that aetiological factors other than hyperglycaemia are important in the pathogenesis of this disorder.

Differences in the availability of systemic insulin or $\mathrm{C}$ peptide or both in the two types of diabetes are likely to be of pathogenetic importance. Lack of insulin or $\mathrm{C}$ peptide or both appears to contribute to the more severe axonal atrophy, loss of axons and to the development of axo-glial disjunction in Type I diabetes. This agrees with the beneficial effect of C-peptide supplementation on diabetic neuropathy in Type I diabetic patients and animal models. Therefore one of the challenges in the next years will be to understand the mechanistic differences between Type I and Type II diabetic neuropathy, since this possibly will translate into different treatment strategies in the two types of diabetic neuropathy. Another challenge will be to gain a better understanding of the sequence and precise interrelations between various metabolic and molecular events to establish a hierarchy as to their relevance.

Acknowledgements. This review study was supported by the Juvenile Diabetes Foundation International and the Thomas Foundation. The authors thank Ms. D. Parus for preparing the manuscript.

\section{References}

1. Greene DA, Sima AAF, Feldman EL, Stevens MJ (1997) Diabetic neuropathy. In: Rifkin H, Porte D, Sherwin R (eds) Ellenberg and Rifkin diabetes mellitus. Appleton and Lange, Stanford Conn. pp 1009-1076

2. Pickup JC, Williams G (1994) Chronic complications of diabetes. Blackwell Science, London

3. Pirart J (1978) Diabetes mellitus and its degenerative complications: a prospective study of 4400 patients observed. Diabetes Care 1: 168-188
4. Thomas PK (1997) Clinical features and investigation of diabetic somatic peripheral neuropathy. Clin Neurosci 4: 341-345

5. Yagihashi S (1995) Pathology and pathogenetic mechanisms of diabetic neuropathy. Diab Metab Rev 11: 193-225

6. Greene DA, Sima AAF, Stevens MJ et al. (1993) Aldose reductase inhibitors: an approach to the treatment of diabetic nerve damage. Diabetes Metab Rev 9: 189-217

7. Cameron NE, Cotter MA (1994) The relationship of vascular changes to metabolic factors in diabetes mellitus and their role in the development of peripheral nerve complications. Diabetes Metab Rev 10: 189-224

8. Sima AAF, Ristic H, Merry A, Kamijo M, Lattimer SA, Stevens MJ, Greene DA (1996) The primary preventional and secondary interventative effects of acetyl-L-carnitine on diabetic neuropathy in the BB/W-rat. J Clin Invest 97: 1900-1907

9. Dyck PJ, Zimmerman BR, Vilen TH, Minnerath SR, Karnes JL, Yao JK, Poduslo JF (1988) Nerve glucose, fructose, sorbitol, myo-inositol, and fiber degeneration and regeneration in diabetic neuropathy. N Engl J Med 319: 542-548

10. Ishii DN (1995) Implications of insulin-like growth factors in the pathogenesis of diabetic neuropathy. Brain Res Rev 20: 47-67

11. Hall KE, Sima AAF, Wiley JW (1996) Opiate-mediated inhibition of calcium signaling is decreased in DRG neurons from the diabetic BB/W-rat. J Clin Invest 97: 1165-1172

12. The Diabetes Control and Complications Trial Research Group (1993) The effect of intensive treatment of diabetes on the development and progression of long-term complications in insulin-dependent diabetes mellitus. New Engl $\mathbf{J}$ Med 329: 977-986

13. Sima AAF, Nathaniel V, Bril V, McEwen TAJ, Greene DA (1988) Histopathological heterogeneity of neuropathy in insulin-dependent and non-insulin-dependent diabetes, and demonstration of axo-glial dysjunction in human diabetic neuropathy. J Clin Invest 82: 349-364

14. Sima AAF, Zhang W-X, Xu G, Sugimoto K, Wahren J (1998) C-peptide treatment has an ameliorating effect on type-1 diabetic neuropathy. Proc Diabetes Compl Conference Joslin 100th Anniversary, Boston, MA

15. Ido Y, Vindigni A, Chang K et al. (1997) Prevention of vascular and neural dysfunction in diabetic rats by $\mathrm{C}$-peptide. Science 777: 563-566

16. Johansson B-L, Borg K, Fernquist-Forbes E, Odergren T, Remahl S, Wahren J (1996) C-peptide improves autonomic nerve function in patients with type-1 diabetes. Diabetologia 39: 687-695

17. Heesom AE, Hibberd ML, Millward A, Demaine AG (1997) Polymorphism in the 5 '-end of the aldose reductase gene is strongly associated with the development of diabetic nephropathy in type 1 diabetes. Diabetes 46: 287-291

18. Ko BC, Lam KS, Wat NM, Chung SS (1995) An (A-C)n dinucleotide repeat polymorphic marker at the $5^{\prime}$ end of the aldose reductase gene is associated with early-onset diabetic retinopathy in NIDDM patients. Diabetes 44: 727-732

19. Yagihashi S, Kamijo M, Nagai K (1991) Peripheral neuropathy in diabetic animals: heterogenous expression of neuropathic patterns in different animal models. In: Shafrir E (ed) Frontiers in Diabetes Research. Lessons from animal diabetes, vol 3. Smith Gordon, London, pp 459-463

20. Sharma AK, Richard PA (1999) Diabetic neuropathy in various animal models. In: Sima AAF (ed) Frontiers in Animal Diabetes Research. Chronic complication in diabetes. Harwood Acad. Publ., Amsterdam, pp 131-165

21. Yagihashi S, Sugimoto K, Wada R (1994) Different neuropathic patterns between type-I and type-II animal models. In: Sakamoto N, Alberti KGMM, Hotta N (eds) Pathogen- 
esis and Treatment of NIDDM and its Related Problems. Elsevier, Amsterdam, pp 401-405

22. Sharma AK, Thomas PK (1987) Animal models: pathology and pathophysiology. In: Dyck PJ, Thomas PK, Ashbury AK, Winegrad AL, Porte D Jr (eds) Diabetic Neuropathy. Saunders, Philadelphia, pp 237-252

23. Jakobsen J (1976) Axonal dwindling in early experimental diabetes. II. A study of isolated nerve fibres. Diabetologia 12: 539-546

24. Yagihashi S, Kamijo M, Watanabe K (1990) Reduced myelinated fiber size correlates with loss of axonal neurofilaments in peripheral nerve of chronically streptozotocin diabetic rats. Am J Pathol 136: 1365-1373

25. Medori R, Antilio-Gambetti L, Jenich H, Gambetti P (1988) Changes in axon size and slow axonal transport are related in experimental diabetic neuropathy. Neurology 38: 597-601

26. Sima AAF, Zhang W-X, Tai J, Tze WJ, Nathaniel V (1988) Diabetic neuropathy in STZ-induced diabetic rat and effect of allogenic islet cell transplantation. Morphometric analysis. Diabetes 37: 1129-1136

27. Yagihashi S, Kamijo M, Ido Y, Mirrless D (1990) Effects of long-term aldose reductase inhibition on development of experimental diabetic neuropathy: ultrastructural and morphometric studies of sural nerve in streptozotocin-induced diabetic rats. Diabetes 39: 690-696

28. Sugimura K, Windebank AJ, Natarajan V, Lambert EH, Schmid HH, Dyck PJ (1980) Interstitial hyperosmolality may cause axis cylinder shrinkage in streptozotocin diabetic nerve. J Neuropath Exp Neurol 39: 710-721

29. Sharma AK, Bajada S, Thomas PK (1981) Influence of streptozotocin-induced diabetes on myelinated nerve fiber maturation and on body growth in the rat. Acta Neuropathol (Berl) 53: 257-265

30. Cameron NE, Cotter MA (1999) Oxidative stress and abnormal lipid metabolism in diabetic complications. In: Sima AAF (ed) Frontiers in Animal Diabetes Research. Chronic Complications in Diabetes. Harwood, Amsterdam, pp 97-130

31. Hellweg R, Hartung H-D (1990) Endogenous levels of nerve growth factor [NGF] are altered in experimental diabetes mellitus: a possible role for NGF in the pathogenesis of diabetic neuropathy. J Neurosci Res 26: 258-267

32. Verge VMK, Tetzlaff W, Bisby MA, Richardson PM (1990) Influence of nerve growth factor on neurofilament gene expression in mature primary sensory neurons. J Neurosci 10: 2018-2025

33. Nagata H, Brimijoin S, Low P, Schmelzer JD (1987) Slow axonal transport in experimental hypoxia and in neuropathy induced by p-bromophenylacetylurea. Brain Res 432: 319-326

34. Schmidt RE, Scharp DW (1982) Axonal dystrophy in experimental diabetic neuropathy. Diabetes 32: 761-770

35. Cameron NE, Cotter MA, Dines KC, Robertson S, Cox D (1993) The effects of evening primrose oil on peripheral nerve function and capillarization in streptozotocin-diabetic rats: modulation by the cyclo-oxygenase inhibitor flurbiprofen. Br J Pharmacol 109: 972-979

36. Felten DL (1979) Spinal cord alterations in streptozotocininduced diabetes. Anat Rec 193: 741

37. Sidenius P, Jakobsen J (1980) Reduced perikaryal volume of lower motor and primary sensory neurons in early experimental diabetes. Diabetes 29: 182-186

38. Sasaki H, Schmelzer JD, Zollman PJ, Low PA (1997) Neuropathology and blood flow of nerve, spinal roots and dorsal root ganglia in longstanding diabetic rats. Acta Neuropathol (Berl) 93: 118-128
39. Russel JW, Windebank AJ, Schenone A, Feldman EL (1998) Insulin-like growth factor-1 prevents apoptosis in neurons after growth factor withdrawal. J Neurobiol 36: 455-467

40. Marliss EB, Nakhooda AF, Poussier P, Sima AAF (1982) The diabetic syndrome of the BB-Wistar rat. Possible relevance to type-1 (insulin dependent) diabetes in man. Diabetologia 22: 225-232

41. Sima AAF (1985) Can the BB-rat help to unravel diabetic neuropathy? Annotation. Neuropathol Appl Neurobiol 11: 253-264

42. Yagihashi S, Sima AAF (1986) Diabetic autonomic neuropathy in the BB-rat. Ultrastructural and morphometric changes in parasympathetic nerves. Diabetes 35: 733-743

43. Chakrabarti S, Zhang W-X, Sima AAF (1991) Optic neuropathy in the diabetic BB-rat. Adv Exp Med Biol 291: 257-264

44. Sima AAF, Lattimer SA, Yagihashi S, Greene DA (1986) "Axo-glial dysjunction": a novel structural lesion that accounts for poorly reversible slowing of nerve conduction in the spontaneously diabetic BB-rat. J Clin Invest 77: 474-484

45. Greene DA, Chakrabarti S, Lattimer SA, Sima AAF (1987) Role of sorbitol accumulation and myoinositol depletion in paranodal swelling of large myelinated nerve fibers in the insulin-deficient spontaneously diabetic biobreeding rat. J Clin Invest 79: 1479-1485

46. Sima AAF, Prashar A, Zhang W-X, Chakrabarti S, Greene DA (1990) Preventive effect of long term aldose reductase inhibition (Ponalrestat) on nerve conduction and sural nerve structure in the spontaneously diabetic BB-rat. J Clin Invest 85: 1410-1420

47. Sima AAF, Brismar T (1985) Reversible diabetic nerve dysfunction. Structural correlates to electrophysiological abnormalities. Ann Neurol 18: 21-29

48. Brismar T, Sima AAF (1981) Changes in nodal function in nerve fibres of the spontaneously diabetic BB-Wistar rat. Potential clamp analysis. Acta Physiol Scand 113: 499-506

49. Cherian PV, Kamijo M, Angelides KJ, Sima AAF (1996) Nodal $\mathrm{Na}^{+}$-channel displacement is associated with nerve conduction slowing in the chronically diabetic BB/W-rat. Prevention by an aldose reductase inhibitor. J Diabetes Complications 10: 192-200

50. Magnani P, Cherian PV, Gould GW Greene DA, Sima AAF, Brosius FC III (1996) Glucose transporters in rat peripheral nerve: paranodal expression of GLUT1 and GLUT3. Metabolism 45: 1466-1473

51. Merry AC, Yamamoto K, Sima AAF (1998) Imbalances in N-CAM, SAM and polysialic acid may underlie the paranodal ionchannel barrier defect in diabetic neuropathy. Diabetes Res Clin Prac 40: 153-160

52. Sima AAF, Lorusso AC, Thibert P (1982) Distal symmetric polyneuropathy in the spontaneously diabetic BB-Wistar rat. An ultrastructural and teased fiber study. Acta Neuropathol (Berl) 58: 39-47

53. Sima AAF, Yagihashi S (1986) Central-peripheral distal axonopathy in the spontaneously diabetic BB-rat: ultrastructural and morphometric findings. Diabetes Res Clin Prac 1: 289-298

54. Zhang W-X, Chakrabarti S, Greene DA, Sima AAF (1990) Diabetic autonomic neuropathy in BB-rats: the effect of ARI-treatment on heart-rate variability and vagus nerve structure. Diabetes 39: 613-618

55. Paro M, Prosdocimi M, Zhang W-X, Sutherland G, Sima AAF (1989) Autonomic neuropathy in the BB-rat. Alterations in bladder function. Diabetes 38: 1023-1030

56. Sima AAF, Zhang W-X, Cherian PV, Chakrabarti S (1992) Impaired visual evoked potentials and primary axonopathy 
of the optic nerve in the diabetic BB/W-rat. Diabetologia 35: 602-607

57. Sima AAF, Thibert P (1982) Proximal motor neuropathy in the BB-Wistar rat. Diabetes 31: 784-788

58. Kamijo M, Merry AC, Cherian PV, Akdas G, Sima AAF (1996) Nerve fiber regeneration following axotomy in the diabetic BB/W-rat. The effect of ARI-treatment. J Diabetes Complications 10: 183-191

59. Sima AAF, Merry AC, Levitan I (1997) Increased regeneration in ARI-treated diabetic nerve is associated with upregulation of IGF-1 and NGF receptors. Exp Clin Endocrinol Diabetes 105: 60-62

60. Robertson DM, Sima AAF (1980) Diabetic neuropathy in the mutant mouse $[\mathrm{C} 57 / \mathrm{BL} / \mathrm{Ks}(\mathrm{db} / \mathrm{db})]$. A morphometric study. Diabetes 29: 60-67

61. Moore SA, Peterson RG, Felten DL, Cartwright TR, O'Connor BL (1980) Reduced sensory and motor conduction velocity in 25 -week-old diabetic $[\mathrm{C} 57 \mathrm{BL} / \mathrm{Ks}(\mathrm{db} / \mathrm{db})]$ mice. Exp Neurol 70: 548-555

62. Sharma AK, Thomas PK, Gabriel G, Stolinski C, Dockery P, Hollins GW (1983) Peripheral nerve abnormalities in the diabetic mutant mouse. Diabetes 32: 1152-1160

63. Peterson RG, Sharma AK, Little L, Neel MA, Potter CG, Eichberg J (1988) Peripheral nerve abnormalities in Wistar fatty diabetic rats. In: Shaffir E, Renold AE (eds) Frontiers in Diabetic Research. Lessons from Animal Diabetes, vol 2. John Libbey, London

64. Peterson RG, Little LA, Neel MA (1990) WKY fatty rat as a model of obesity and non-insulin-dependent diabetes mellitus. Institute of Laboratory Animal Resources News 32: 13

65. Yagihashi S, Wada RI, Kamijo M, Nagai K (1993) Peripheral neuropathy in the WBN/Kob rat with chronic pancreatitis and spontaneous diabetes. Lab Invest 68: 296-307

66. Sima AAF, Kommaraju SS, Hall D, Shy ME (1998) Absence of paranodal pathology in type-2 BB/Z-rats accounts for milder functional deficits compared to type-1 diabetic neuropathy. Diabetes 47: A136

67. Stevens MJ, Lattimer SA, Kamijo M, Van Huysen C, Sima AAF, Greene DA (1993) Osmotically induced nerve taurine depletion and the compatible osmolyte hypothesis in experimental diabetic neuropathy in the rat. Diabetologia 36: 608-614

68. Greene DA, Chakrabarti S, Lattimer SA, Sima AAF (1987) Role of sorbitol accumulation and myoinositol depletion in paranodal swelling of large myelinated nerve fibers in the insulin-deficient spontaneously diabetic biobredding rat. J Clin Invest 79: 1479-1485

69. Mayer JH, Tomlinson DR (1983) Prevention of defects of axonal transport and nerve conduction velocity by oral administration of myo-inositol or an ARI in streptozotocindiabetic rats. Diabetologia 25: 433-438

70. Winegrad AL (1987) Banting Lecture 1986. Does a common mechanism induce the diverse complications of diabetes? Diabetes 36: 396-406

71. Zhu X, Eichberg J (1990) 1,2-Diacyl-glycerol content and its arachidonyl-containing species are reduced in sciatic nerve from streptozotocin-induced diabetic rats. J Neurochem 55: 1087-1090

72. Forcier NJ, Mizisin AP, Rimmer MA, Powell HC (1991) Cellular pathology of the nerve microenvironment in galactose intoxication. J Neuropath Exp Neurol 50: 235-255

73. Calcutt NA, Tomlinson DR, Biswas S (1990) Coexistence of nerve conduction deficit with increased $\mathrm{Na}^{+}-\mathrm{K}^{+}$-ATPase activity in galactose-fed mice. Implications for polyol pathway and diabetic neuropathy. Diabetes 39: 663-666

74. Ahlgren SC, Levine JD (1994) Protein kinase C inhibitors decrease hyperalgesia and C-fiber hyperexcitability in the streptozotocin-diabetic rat. J Neurophysiol 72: 684-692
75. Williamson JR, Chang K, Frangos M et al. (1993) Hyperglycemic pseudohypoxia and diabetic complications. Diabetes 42: 801-813

76. Sonobe M, Yasuda H, Hisanaga T et al. (1991) Amelioration of nerve $\mathrm{Na}^{+}-\mathrm{K}^{+}$-ATPase activity independently of myo-inositol level by PGE 1 analogue OP-1206 $\alpha$-CD in streptozotocin-induced diabetic rats. Diabetes 40: 726-730

77. Yasuda H, Sonobe M, Hatanaka I et al. (1988) A new prostaglandin E1 analogue (TFC-612) prevents a decrease in motor nerve conduction velocity in streptozotocin-diabetic rats. Biochem Biophys Res Commun 150: 225-230

78. Lowitt S, Malone JI, Salem AF, Korthals J, Benford S (1995) Acetyl-L-carnitine corrects altered peripheral nerve function in experimental diabetes. Metabolism 44: 677-680

79. Hohman TC, Banas D, Basso M, Cotter MA, Cameron NE (1997) Increased oxidative stress in experimental diabetic neuropathy. Diabetologia 40 [Suppl 1]: A549

80. Lou MF, Dickerson JE, Garadi R, York BM (1988) Glutathione depletion in the lens of galactosemic and diabetic rats. Exp Eye Res 46: 517-530

81. Tilton RG, Chang K, Nyengaard JR, van den Eden M, Kilo C, Williamson JR (1995) Inhibition of sorbitol dehydrogenase. Effects on vascular and neural dysfunction in streptozotocin-induced diabetic rats. Diabetes 44: 234-242

82. Cameron NE, Cotter MA, Basso M, Hohman TC (1997) Comparison of the effects of inhibitors and aldose reductase and sorbitol dehydrogenase on neurovascular function, nerve conduction and tissue polyol-pathway metabolites in streptozotocin-diabetic rats. Diabetologia 40: 271-281

83. Schmidt RE, Dorsey DA, Beaudet LN, Plurad SB, Williamson JR, Ido Y (1998) Effect of sorbitol dehydrogenase inhibition on experimental diabetic autonomic neuropathy. J Neuropath Exp Neurol 57: 1175-1189

84. Stevens MJ, Lattimer SA, Feldman EL et al. (1996) AcetylL-carnitine deficiency as a cause of altered nerve myo-inositol content, $\mathrm{Na}^{+} / \mathrm{K}^{+}$-ATPase activity and motor conduction velocity in the streptozotocin diabetic rat. Metabolism 45: $865-872$

85. Hotta N, Koh N, Sakakibara F et al. (1996) Effect of proprionyl-L-carnitine on motor nerve conduction, autonomic cardiac function and nerve blood flow in rats with streptozotocin-induced diabetes: comparison with an aldose reductase inhibitor. J Pharmacol Exp Ther 276: 49-55

86. Cotter MA, Cameron NE, Keegan A, Dines KC (1995) Effects of acetyl- and proprionyl-L-carnitine on peripheral nerve function and vascular supply in experimental diabetes. Metabolism 44: 1209-1214

87. Sima AAF, Srinivas PR, Kommaraju S, Venna S, Wahren J, Grunberger G (1998) Enhancement of insulin receptor activity by C-peptide. Diabetologia 41 [Suppl 1]: A177

88. Mizisin AP, Powell C (1993) Schwann-cell injury is attenuated by aldose reductase inhibition in galactose intoxication. J Neuropath Exp Neurol 52: 78-86

89. Kamijo M, Basso M, Cherian PV, Hohman TC, Sima AAF (1994) Galactosemia produces ARI-preventable nodal changes similar to those of diabetic neuropathy. Diabetes Res Clin Pract 25: 117-129

90. Yagihashi S, Yamagishi SI, Wada R et al. (1996) Galactosemic neuropathy in transgenic mice for human aldose reductase. Diabetes 45: 56-59

91. Bianchi R, Marelli C, Marini P (1990) Diabetic neuropathy in $\mathrm{db} / \mathrm{db}$ mice develops independently of changes in ATPase and aldose reductase. A biochemical and immunocytochemical study. Diabetologia 33: 131-136

92. Sima AAF, Bril V, Nathaniel V et al. (1988) Regeneration and repair of myelinated fibers in sural nerve biopsies from patients with diabetic neuropathy treated with an aldose reductase inhibitor. N Engl J Med 319: 548-555 
93. Van Dam PS, Van Asbeck BS, Erkeleus DW, Marx JJM, Gispen W-H, Bravenboer B (1995) The role of oxidative stress in neuropathy and other diabetic complications. Diabetes Metab Rev 11: 181-192

94. Baynes JW (1991) Role of oxidative stress in the development of complications in diabetes. Diabetes 40: 405-412

95. Wolff SP (1993) Diabetes mellitus and free radicals. Free radicals, transition metals and oxidative stress in the aetiology of diabetes mellitus and complications. Br Med Bull 49: 642-652

96. McCord JM (1985) Oxygen-derived free radicals in postischemic tissue injury. N Engl J Med 312: 159-163

97. Hyslop PA, Hinshaw DB, Halsey WA Jr et al. (1988) Mechanism of oxidant mediated cell injury: the glycolytic and mitochondrial pathways of ADP phosphorylation are major intracellular targets inactivated by hydrogen peroxide. J Biol Chem 263: 1665-1675

98. Maxfield EK, Cameron NE, Cotter MA, Dines KC (1993) Angiotensein II receptor blockade improves nerve function, modulates nerve blood flow and stimulates endoneurial angiogenesis in streptozotocin-diabetic rats. Diabetologia 36: 1230-1237

99. Maxfield EK, Love A, Cotter MA, Cameron NE (1995) Nerve function and regeneration in diabetic rats: effects of ZD-7155, an $\mathrm{AT}_{1}$ receptor antagonist. Am J Physiol 269: E530-E537

100. Hallab M, Bled F, Ebrau JM et al. (1992) Elevated serum angiotensin I converting enzyme activity in type-1, insulindependent diabetic subjects with persistent microalbuminuria. Acta Diabetol 29: 82-85

101. Cameron NE, Cotter MA, Archibald V, Dines KC, Maxfield EK (1994) Anti-oxidant and pro-oxidant effects on nerve conduction velocity, endoneurial blood flow and oxygen tension in non-diabetic and streptozotocin-diabetic rats. Diabetologia 37: 449-459

102. Rubanyi GM, Polokoff MA (1994) Endothelins: molecular biology, biochemistry, pharmacology, physiology, and pathophysiology. Pharmcol Rev 46: 325-415

103. Cameron NE, Cotter MA (1996) Effects of a non-peptide endothelin-1 $\mathrm{ET}_{\mathrm{A}}$ antagonist on neurovascular function in diabetic rats: interaction with the renin-angiotensin system. J Pharmacol Exp Ther 278: 1262-1268

104. Stevens EJ, Tomlinson DR (1995) Effects of endothelin receptor antagonism with bosentan on peripheral nerve function in experimental diabetes. Br J Pharmacol 115: 373-379

105. Ceriello A (1993) Coagulation activation in diabetes mellitus: the role of hyperglycaemia and therapeutic prospects. Diabetologia 36: 1119-1125

106. Faruqi R, de la Motte C, DiCorleto PE (1994) $\alpha$-tocopherol inhibits agonist-induced monocytic cell adhesion to cultured human endothelial cells. J Clin Invest 94: 592-600

107. Low PA, Lagerlund TD, McManis PG (1989) Nerve blood flow and oxygen delivery in normal, diabetic and ischemic neuropathy. Int Rev Neurobiol 31: 355-438

108. Cameron NE, Cotter MA, Robertson S (1992) Angiotensin converting enzyme inhibition prevents the development of muscle and nerve dysfunction and stimulates angiogenesis in streptozotocin-diabetic rats. Diabetologia 35: $12-18$

109. Olbrich A, Rosen P, Hilgers RD, Dhein S (1996) Fosinopril improves regulation of vascular tone in mesenteric bed of diabetic rats. J Cardiovasc Pharmacol 27: 187-194

110. Gryglewski RJ, Palmer RMJ, Moncado S (1986) Superoxide anion is involved in the breakdown of endotheliumderived vascular relaxing factor. Nature 320: 454-456

111. Tesfamariam B, Cohen RA (1992) Free radicals mediate endothelial cell dysfunction caused by elevated glucose. Am J Physiol 263: H321-H326
112. Taylor PD, Poston L (1994) The effect of hyperglycemia on function of rat isolated mesenteric resistance artery. $\mathrm{Br} \mathbf{J}$ Pharmacol 113: 801-808

113. Keegan A, Cotter MA, Cameron NE (1997) Autonomic neuropathy, corpus cavernosum innervation and endothelial responses: diabetic defects prevented by alpha-lipoic acid in rats. J Peripheral Nerv System 2: 277

114. Love A, Cotter MA, Cameron NE (1996) Effects of the sulphydryl donor N-acetyl-L-cysteine on nerve conduction, perfusion, maturation and regeneration following freeze damage in diabetic rats. Eur J Clin Invest 26: 698-706

115. Love A, Cotter MA, Cameron NE (1997) Effects of alpha tocopherol on nerve conduction velocity and regeneration following freeze lesion in immature diabetic rats. Naunyn Schmiedebergs Arch Pharmacol 355: 126-130

116. Cameron NE, Cotter MA (1997) Metabolic and vascular factors in the pathogenesis of diabetic neuropathy. Diabetes 46 [Suppl 2]: S31-S37

117. Vlassara H (1994) Recent progress on the biologic and clinical significance of advanced glycosylatyion end products. J Lab Clin Med 124: 19-30

118. Requena JR, Baynes JW (1999) Studies in animal models on the role of glycation and advanced glycation end-products (AGE:s) in the pathogenesis of diabetic complications: pitfalls and limitations. In: Sima AAF (ed) Frontiers in Animal Diabetes Research. Chronic complications in diabetes. Harwood, Amsterdam, pp 43-69

119. Wells-Knecht KJ, Lyons TJ, McCance DR, Thorpe SR, Feather MS, Baynes JW (1994) 3-Deoxyfructose concentrations are increased in human plasma and urine in diabetes. Diabetes 43: 1152-1156

120. Glomb M, Monnier VM (1995) Mechanism of protein modification by glyoxal and glycoaldehyde, reactive intermediates in the Maillard reaction. J Biol Chem 270: 10017-10026

121. Vlassara H, Brownlee M, Cerami A (1981) Nonenzymatic glycosylation of peripheral nerve protein in diabetes mellitus. Proc Natl Acad Sci USA 78: 5190-5192

122. Vlassara H, Brownlee M, Cerami A (1983) Excessive nonenzymatic glycosylation of peripheral and central nervous system myelin components in diabetic rats. Diabetes 32: 670-674

123. Weimbs T, Stoffel W (1994) Topology of CNS myelin proteolipid protein: evidence for the nonenzymatic glycosylation of extracytoplasmic domains in normal and diabetic animals. Biochemistry 33: 10408-10415

124. Vlassara H, Brownlee M, Cerami A (1985) Recognition and uptake of human diabetic peripheral nerve myelin by macrophages. Diabetes 34: 553-557

125. Ryle C, Leow CK, Donaghy M (1997) Nonenzymatic glycation of peripheral and central nervous system proteins in experimental diabetes mellitus. Muscle Nerve 20: 577-584

126. Cullum NA, Mahon J, Stringer K, McLean WG (1991) Glycation of rat sciatic nerve tubulin in experimental diabetic mellitus. Diabetologia 34: 387-389

127. Williams SK, Howarth NL, Devenny JJ, Bitensky MW (1982) Structural and functional consequences of increased tubulin glycosylation in diabetes mellitus. Proc Natl Acad Sci USA 79: 6546-6550

128. Federoff JH, Lawrence D, Brownlee M (1993) Nonenzymatic glycosylation of laminin and the laminin peptide CIKVAVS inhibits neurite outgrowth. Diabetes 42: 509-513

129. Takagi Y, Kashiwagi A, Tanaka Y, Asahina T, Kikkawa R, Shigeta Y (1995) Significance of fructose-induced protein oxidation and formation of advanced glycation end product. J Diabetes Complications 9: 87-91

130. Dvornik D (1987) Aldose reductase inhibition. An approach to the prevention of diabetic complications. McGraw Hill, New York, NY 
131. Lal S, Szwergold BS, Taylor AH et al. (1995) Metabolism of fructose-3-phosphate in the diabetic rat lens. Arch Biochem Biophys 318: 191-199

132. Phillips SA, Thornalley PJ (1993) The formation of methylglyoxal from triose phosphates. Investigation using a specific assay for methylglyoxal. Eur J Biochem 212: 101-105

133. Baynes JW, Thorpe SR (1999) Role of oxidative stress in diabetic complications. A new perspective on an old paradigm. Diabetes 48: 1-9

134. Hoshi A, Takahashi M, Fujii J et al. (1996) Glycation and inactivation of sorbitol dehydrogenase in normal and diabetic rats. Biochem J 318: 119-123

135. Soulis-Liparota T, Cooper ME, Dunlop M, Jerums G (1995) The relative roles of advanced glycation, oxidation and aldose reductase inhibition in the development of experimental diabetic nephropathy in the Sprague-Dawley rat. Diabetologia 38: 387-394

136. Phillips SA, Mirrlees D, Thornalley PJ (1993) Modification of the glyoxalase system in streptozotocin-induced diabetic rats. Effect of the aldose reductase inhibitor statil. Biochem Pharmacol 46: 805-811

137. Arai K, Maguchi S, Fujii S, Ishibashi H, Oikawa K, Taniguchi N (1987) Glycation and inactivation of human $\mathrm{Cu}-\mathrm{Zn}$ superoxide dismutase. Identification of the in vitro glycated sites. J Biol Chem 262: 16969-16972

138. Bierhaus A, Chevion S, Chevion M et al. (1997) Advanced glycation end product-induced activation of NF- $x$ B is suppressed by $\alpha$-lipoic acid in cultured endothelial cells. Diabetes 46 : $1481-1490$

139. Sugimoto K, Nishizawa Y, Horiuchi S, Yagihashi S (1997) Localization in human diabetic peripheral nerve of $\mathrm{N}^{\varepsilon}$-Carboxymethyllysine-protein adducts, one of advanced glycation end products. Diabetologia 40: 1380-1387

140. Brownlee M, Vlassara H, Kooney A, Ulrich P, Cerani A (1986) Aminoguanidine prevents diabetes-induced arterial wall protein cross-linking. Science 232: 1629-1632

141. Yagihashi S, Kamijo M, Baba M, Yagihashi N, Nagai K (1992) Effect of aminoguanidine of functional and structural abnormalities in peripheral nerve of STZ-induced diabetic rats. Diabetes 41: 47-52

142. Tomlinson DR, Fernyhough P (1999) Neurotrophism in diabetic neuropathy. In: Sima AAF (ed) Frontiers in Animal Diabetes Research. Chronic complications in diabetes. Harwood, Amsterdam, pp 167-182

143. Schmidt RE, Graban GG, Yip HK (1986) Retrograde axonal transport of $\left[{ }^{125} \mathrm{I}\right]$-nerve growth factor in ileal mesenteric nerves vitro: effect of streptozotocin diabetes. Brain Res 378: 325-336

144. DiStefano PS, Friedman B, Radziejewski C, Alexander C (1992) The neurotrophins BDNF, NT-3 and NGF display distinct patterns of retrograde axonal transport in peripheral and central neurons. Neuron 8: 983-993

145. Fernyhough P, Brewster NJ, Diemel LT, Tomlinson DR (1993) Nerve growth factor mRNA in diabetic rat sciatic nerve; effects of neurtrophic factor treatment. Br J Pharmacol 110: 173P

146. Fernyhough P, Carrington AL, Tomlinson DR (1992) Reduced nerve growth factor mRNA in skin of diabetic rats: effects of insulin. Br J Pharmacol 107: 462P

147. Gold BG, Mobley WC, Matheson SF (1991) Regulation of axonal caliber, neurofilament content, and nuclear localiza- tion in mature sensory neurons by nerve growth factor. $\mathbf{J}$ Neurosci 11: 943-955

148. Wang C, Li Y, Wible B, Angelides KJ, Ishii DN (1992) Effects of insulin and insulin-like growth factors on neurofilament mRNA and tubulin mRNA content in human neuroblastoma SH-Y5Y cells. Brain Res Mol Brain Res 13: 289-300

149. Heumann R, Hengerer B, Brown M, Perry H (1991) Molecular mechanisms leading to lesion-induced increases in nerve growth factor synthesis. Ann NY Acad Sci 633: $581-582$

150. Whitworth IH, Terenghi G, Green CJ, Brown RA, Stevens E, Tomlinson DR (1995) Targeted delivery of nerve growth factor via fibronectin conduits assists nerve regeneration in control and diabetic rats. Eur J Neurosci 7: 2220-2225

151. Apfel SC, Kessler JA, Adornato BT, Litchy WJ, Sanders C, Rask CA (1998) Recombinant human nerve growth factor in the treatment of diabetic polyneuropathy. NGF Study Group. Neurol 51: 695-702

152. Sima AAF, Levitan I, Ristic H, Kamijo M (1995) Nerve fiber regeneration in the spontaneously diabetic BB/W-rat. In: Hotta N, Greene DA, Ward JD, Sima AAf, Boulton AJM (eds) Diabetic Neuropathy: New Concepts and Insights. Elsvier Science BV, Amsterdam, pp 27-36

153. Ishii DN, Lupien SB (1995) Insulin-like growth factors protect against diabetic neuropathy: effects on sensory nerve regeneration in rats. J Neurosci Res 40: 138-144

154. Fernyhough P, Mill JF, Roberts JL, Ishii DN (1989) Stabilization of tubulin mRNAs by insulin and insulin-like growth factor 1 during neurite formation. Mol Brain Res 6: 109-120

155. Feldman EL, Sullivan KA, Kim B, Russell JW (1997) Insulin-like growth factors regulate neuronal differentiation and survival. Neurobiol Dis 4: 201-214

156. Cheng HL, Feldman EL (1997) Insulin-like growth factor-1 (IGF-1) and IGF binding protein-5 in Schwann cell differentiation. J Cell Physiol 171: 161-167

157. Lyons TJ (1991) Oxidised low density lipoproteins - a role in the pathogenesis of atherosclerosis in diabetes. Diabet Med 8: 411-419

158. Horrobin DF, Carmichael H (1992) Essential fatty acids in relation to diabetes. In: Horrobin DF (ed) Treatment of diabetic neuropathy, a new approach. Churchill Livingstone, London

159. Ward KK, Low PA, Schmelzer JD, Zochodne DW (1989) Prostacyclin and noradrenaline in peripheral nerve of chronic experimental diabetes in rats. Brain 112: 197-208

160. Karasu C, Dewhurst M, Stevens EJ, Tomlinson DR (1995) Effects of antioxidant treatment on sciatic nerve dysfunction in streptozotocin-diabetic rats; comparison with essential fatty acids. Diabetologia 38: 129-134

161. Cameron NE, Cotter MA, Robertson S (1991) Essential fatty acid diet supplementation: effects on peripheral nerve and skeletal muscle function and capillarization in streptozotocin-induced diabetic rats. Diabetes 40: 532-539

162. Dines KC, Cotter MA, Cameron NE (1995) Nerve function in galactosemic rats: effects of evening primrose oil and doxazosin. Eur J Pharmacol 281: 303-309

163. Ido Y, McHowat J, Chang KC et al. (1994) Neural dysfunction and metabolic imbalances in diabetic rats: prevention by acetyl-L-carnitine. Diabetes 43: 1469-1477 